\title{
Studien über die Bedingungen des positiven oder negativen Ausfallens der Gramfärbung bei einigen Bakterien.
}

\author{
Von
}

Dr. Axel Cedercreutz,

Dozent der Dermatologie und Syphilidologie an der Universität Helsingfors, Finland.

In einer früheren Arbeit') habe ich hervorgehoben, wie meines Erachtens die Kokkenflora der menschlichen Haut gar nicht so bunt sei als einige Autoren es gedacht haben, sondern hauptsächlich nur aus verschiedenen Formen eines polymorphen, dem Micrococcus tetragenus sehr nabestehenden Coccus besteht. Alle diese Formen sind Gram-positiv. Auch die Untersuchungen anderer Hautbakteriologen gehen darauf hin, daß die Epidermisflora unter gewöhnlichen Umständen so gut wie ausschließlich Gram-positiv ist.

In gewissem Gegensatz zu dieser Beobachtung hat $\mathrm{Cr}$ onquist $1903^{2}$ ) auf nach Welander mit Wärme behandelten Geschwüren beinahe regelmäßig einen Gram-negativen Diplococcus gefunden, welcher $\mathrm{Cr}$ onquists Beschreibung nach dem polymorphen Hautcoccus morphologisch und kulturell außerordentlich ähnlich ist. Denselben Gram-negativen Coccus hat Cronquist unter feuchtwarmen Umschlägen auf der Haut

1) Cedercreutz, Axel. Recherches sur un coccus polymorphe hote habituel et parasite de la peau humaine. Paris. Steinheil. 1901.

2) Cronquist, Carl. Ein neuer Coccus, unter eigenartigen Umständen auf der Haut angetroffen. Monatsh. f. prakt. Dermatologie. 1903. XXXVI. pag. 645 . 
nachweisen können. Er glaubt, daß es sich um einen Coccus handelt, welcher nur in Feuchtigkeit und Wärme gedeihende Wachstumsbedingungen hat und nennt ihn: „Micrococcus hydrothermicus". Woher dieser Coccus stammte, konnte Cronquist nicht feststellen. In der Luft hat er denselben nicht gefunden und er hielt es aw wahrscheinlichsten, daB der Gram-negative Coccus sehr allgemein an der Hautoberfläche in irgend einer Ruheform vorkäme und nur unter ganz anderen Verhältnissen als sie ihm die normale, trockene Haut darbieten könne, zur Entwicklung gelange. Als Bedingungen seiner Entwicklungsmöglichkeiten hebt $\mathrm{Cr}$ on quist eine stete Feuchtigkeit und eine nicht zu niedrige Temperatur (am liebsten c. $41^{\circ} \mathrm{C}$.) hervor. In sehr vielen von seinen Fällen hat $\mathrm{Cr}$ onqu ist nach genügender Wärmebehandlung ausschließlich den Gram-negativen Coccus züchten können. Bei Kontrolluntersuchungen von der unbehandelten Oberhaut hat anch er nur Gram-positive Kokken mit weißen oder gelben Kulturen gefunden.

Diese Tatsachen haben mich vermuten lassen, daß es sich vielleicht in den $\mathrm{Cr}$ onquistschen Fällen nicht um einen ganz neuen Coccus handelte, sondern daß der gewöhnliche Gram-positive polymorphe Hautcoccus unter gewissen Bedingungen Gram-negativ werden könnte.

Um Material für meine Untersuchungen zu bekommen, fing ich an bei Patienten, die mit feuchtwarmen Umschlägen behandelt waren, nach dem $\mathrm{Cr}$ on $q u$ is $\mathrm{t}$ schen Coccus zu suchen. Für die Erlaubnis, mich hierbei der Patienten der inneren Klinik zu bedienen, bin ich Herrn Dozenten Dr. E. A. von Willebrand zu Dank verpflichtet.

Daß es sich in meinen diesbezüglichen Untersuchungen gar nicht um eine bakteriologische Analyse der mit feuchtwarmen Umschlägen behandelten Haut handelte, will ich ausdrücklich hervorheben. Eine solche Analyse hätte in meinen Fällen, wo zu den Umschlägen ungekochtes Wasserleitungswasser benutzt wurde, gar kein Interesse geboten und außerdem ist es von Cronquist, der mit sterilem Wasser gearbeitet hat, dargetan, daß oft allein der Gram-negative Coccus von der unter dem Umsehlage befindlichen Hautoberfläche gewonnen 
Studien über d. Bed. d. pos. o. neg. Ausf. d. Gramfärb. ete. 357 .

werden kann. In drei ron fünf untersuchten Fällen habe ich überwiegend Kolonien des $\mathrm{Cr}$ onquistschen Coccus bekommen.

$\mathrm{Zu}$ gleicher Zeit entnommene Proben des Wasserleitungswassers gaben auf Agar zahlreiche Bakterienkolonien, meistens Bazillen, aber keine den Cro $\mathrm{u}$ q u i s t schen ähnlichen Diplokokken.

Nachdem ich den Cronquistschen Coccus reingezüchtet hatte, stellte ich mir die Aufgabe zu untersuchen, ob man diesen Gram-negativen Coccus in Gram-positiv verwandeln könnte, und parallel hiermit, ob man den gewöhnlichen Grampositiven Hautcoccus in Gram-negativ zu verwandeln im stande sei. Diese meine erste Aufgabe habe ich später etwas erweitert und habe durch Experimente versucht die Bedingungen der Gra m schen Färbemethode bei einigen Bakterien zu studieren.

Ältere Bakteriologen dachten, daß jede Bakterienart immer sich entweder nach Gram färbte oder nicht; Zwischenstufen gebe es nicht. Die zweifelhaften Ergebnisse sollten auf Fehler in der Färbungstechnik und besonders auf eine nicht richtige Anwendungsart des Alkohols zurückzuführen sein.

Später wurde jedoch von mancher Seite gezeigt, daß ein und derselbe Mikroorganismus bei derselben Ausführung der Gramfärbung sich unter Umständen dieser Färbemethode gegenüber verschieden verhalten könne. Einige dieser $\mathrm{Be}-$ obachtungen gebe ich hier hauptsächlich nach Gotschlich ${ }^{1}$ ) und Grim $\theta^{a}$ ) wieder:

\section{Erhitzung.}

Trommsdorf (1902) gibt an, dab gekochte Hefe und Milzbrandbazillen durch trockenes Erhitzen auf $120^{\circ}$ während 2 Stunden die Alkoholfestigkeit verlieren. Im Gegensatz hierzu behauptet jedoch $\mathrm{N}$ i k i t in e (1898),

1) Gotschlich, E. Allgemeine Morphologie und Biologie der pathogenen Mikroorganismen. In: Handbuch der pathogenen Mikroorganismen, herausgegeben von W. Kolle und A. Wassermann. Erste Lieferung. 1902. G. Fis c her. Jena. pag. 70.

3) Grimme, Arnold. Die wichtigsten Methoden der Bakterienfärbung und ihrer Wirkung auf die Membran, den Protoplasten und die Einschlüsse der Bakterienzelle. Zentralbl. f. Bakteriologie. 1902. XXXII. Nr. 1, 2 u. 3.

Wo bei den folgenden Autornamen die Quelle nicht angegeben wird, ist dieselbe in dem ausführlichen Literaturverzeichnisse von Gots $\mathrm{ch}$ lich oder Grimme zu finden. 
daß Erhitzung auf $160-180^{\circ}$ bei verschiedenen Bakterien die Färbbarkeit nach Gram nicht aufheben soll.

\section{Säuren, Alkalien, Ammoniak.}

Diese Substanzen entnehmen nach längerer Einwirkungsdauer (24 bis 72 Stunden) mehreren Bakterien die Fähigkeit sich nach G ram zu färben. Alkalien wirken schneller als Säuren (Nikitine).

Versuche etwa 24 Stunden alte Zellen von B. tumescens durch kurzes Aufkochen in 5\% Salzsäure oder durch Behandlung mit $5 \%$ Natriumkarbonatlösung oder mit $1 \%$ Kalilauge $z \mathbf{u}$ Gram-negativ zu verwandeln gaben A. Grimme (1902) nur negative Resultate.

\section{Substanzen, welche Fett extrahieren.}

Diese üben nach Nikitine keinen Einfluß aus.

\section{Destilliertes Wasser.}

Braem fand 1889,1) dab Staphylokokken, wenn sie in destilJiertem Wasser aufgeschwemmt sind, mit dem zunehmenden Alter und Verfall die Färbbarkeit nach Gram früh einbüßen. Nach 18tägiger Kultivierung in sterilem Wasser könnten nach $\mathrm{Gram}$ gefärbte Elemente nicht mehr nachgewiesen werden und doch waren die Kokken noch nach 25 Tagen reproduktionsfähig. Sie hatten also sebon lange vor ihrem Absterben die Eigenschaft, sich nach Gram za färben eingebüßt.

\section{Beizen und Fixierungsmittel.}

Wenn Gram-positive Mikroorganismen durch Behandlung mit Säuren oder Alkalien die Fähigkeit sich nach Gram zu färben verloren haben, so bekommen sie diese Fähigkeit durch einstündige Einwirkung Loefflerscher Beize wieder (Nikitine).

Paltauf (1892) gibt an, daß in Gewebsschnitten die Fixierung durch Müllersche Flüssigkeit, Osmiumsäure oder Alkohol ein positives Verhalten gewisser Bakterien der G ra m schen Methode gegenüber hervorrufen könne.

Flügge (1896) erwähnt, daß die Angehörigen der Gruppe des Bacillus sputigenes tenuis, welche aur eine relative Empfänglichkeit für die Gramsche Färbung besitzen, in Schnitten, welche durch Chromsäure oder Osmiumsäure fixiert waren, bei einigen Bazillen die Farbe behaiten, bei anderen nicht.

\section{Alter der Kolonien.}

Zimmermann (1890) beobachtete, daß B. pyocyaneus und andere fluoreszierende Bazillen, welche sonst ausgesprochen $\mathrm{Gram}$-negativ

1) Braem, Curt. Untersuchungen über die Degenerationserscheinungen pathogener Bakterien im destillierten Wasser. Zieglers Beiträge zur pathol. Anat. und zur allgem. Pathol. 1889. VII. 1. pag. 11. 
Studien über d. Bed. d. pos. o. neg. Ausf. d. Gramfärb. etc. 359

sind, in ihren jüngsten Kolonien bei kurzer Entfärbung die Gr a m-Farbe behalten.

Czaplewski (1896) bemerkt, daß das Diphtheriebakterium sich nur in jugendfrischen Exemplaren nach Gram färbt.

\section{Zusammersetzung des Nährbodens.}

Mehrere Autoren haben hervorgehoben, daß die chemische Zusammensetzung des Nährbodens in gewissen Fällen von Einfluß auf das Verhalten der Mikroorganismen der Gra m schen Färbemethode gegenüber ist.

Mills (1892) hat Bazillen aus Eiter nach Gram gefärbt gefunden, dagegen dieselben Bazillen von einer Kultur ungefärbt.

Ebenso hat Wilde (1896) beobachtet, daß ein Kapselbazillus, dem Rückenmark von Mäusen entnommen, die l'ärbung behielt, jedoch anf Nährboden übertragen diese Eigenschaft wieder verlor.

A. Schmidt fand 1892, daB Bakterium coli commune und B. lactis a erogenes bei höherem Fettgehalt des Darmbreies, dem sie entnommen waren, sich nicht entfärbten, während bei niederem Fettgehalt des Darminhaltes sie stets entfärbt wurden. Schmidt hat dann auch experimentell dem erst genannten Bakterium durch längere Kultur auf Buttergelatine ein positives Verhalten bei der Gramfärbung anzazüchten vermocht.

Schmidts Beobachtungen konnten jedoch nicht von $\mathrm{Jacobsthal}$ (1897) und Lehmann and Neumann (1897) bestätigt werden.

\section{Verdauung.}

Papayotin (das eiweißverdauende Ferment des Milchsaftes, der Früchte und Blätter von Carica papaya) hebt nach Nikitine bei vielen Mikroorganismen die Fähigkeit sich nach Gram zu färben auf. Doch ist z. B. für den Milzbrandbazillus eine 67 Stunden währende Einwirkung von einer $1 \%$ Lösung nötig.

Tromsd orf (1902) stellte fest, daß gekochte Hefe durch Behandlung mit Pepsin and Trypsin die Alkoholfestigkeit verliert, aber Grimme (1902), welcher Verdaungsversuche mit B. tumescens und B. Ellenbachense in Pepsin- und Trypsinlösungen anstellte, fand, daB die genannten Bakterien nach der Verdaung die Gramfarbe ebenso gut wie früher behielten.

Ob das Verhalten der Mikroorganismen der Gramschen Färbemethode gegenüber ein auf chemischen Reaktionen beruhende oder nur als ein von der physikalischen Beschaffenheit der Mikroorganismen abhängende ist, wird verschieden beantwortet. Nikitine (1898) und Alfred Fischer (1899) glauben auf Grund ihrer Untersuchungen, daß die Gramsche Methode auf rein physikalische Verschiedenheiten der Bakterien basiert ist. 
Die Mehrzahl der Bakteriologen sieht dagegen in dem positiven Ausfallen dieser Färbemethode den Ausdruck einer chemischen Reaktion und zwar mit Unna die Entstehung einer in Alkohol unlöslichen Verbindung von Jod + Pararosanilin + irgendwelcher Substanz der Bakterienzelle.

Nach Grimmes Untersuchungen soll die Eigenschaft gewisser Bakterien nach Gram gefärbt zu bleiben oder die anderer sich zu entfärben nicht an bestimmte Eigenschaften der Membran geknüpft sein.

Daß die spezifische Färbbarkeit gewisser Bakterien durch ihre chemische Zusammensetzung zum wichtigsten Teil bestimmt wird, geht aus den sehr gewissenhaften Untersuchungen von A u clair und Paris ${ }^{1}$ ) über die Säurefestigkeit der Tuberkelbazillen hervor. Diese Untersuchungen haben für die Beurteilung der Prinzipien der Gramfärbung um so mehr Interesse, da alle säurefesten Bakterien auch alkoholfest sind d. h. sich nach Gram färben. Die genannten Autoren kommen bei ihren Untersuchungen za den Schlaßfolgerungen, daß die Säurefestigkeit des Tuberkelbazillus sowohl von seiner chemischen als physikalischen Zusammensetzung ablängt. Vom chemischen Standpunkt aus sind es drei Substanzgruppen, welche die Säurefestigkeit der 'Tuberkelbazillen bedingen: die fett-wachs. artigen Substanzen, die Proteinsubstanzen und die Cellulose. Aber der physikalisch stark zusammengedrängte Zustand, unter welchem alle diese Substanzen im Tuberkelbazillus vorhanden sind, gehört noch dazu, um dem Bazillus Säurefestigkeit zu verleihen. Durch diesen physikalischen Zustand nehmen die Bazillen nur unter gewissen günstigen Bedingungen (Erwärmen, Durchtränken mit Karbolsäurelösung oder mit Anilinöl) den Farbstoff auf, aber wenn sie einmal gefärbt sind, behalten sie dank dieser physikalischen Beschaffenheit die Farbe länger als sonstige Bakterien und leisten der Einwirkung verdünnter Säuren und absoluten Alkohols einen effektiven Widerstand.

Im Einklange hiermit stehen die Ergebnisse einiger Untersuchungen von Bienenstock (1886), Gottstein (1886) und Weber (1902). Die genannten Autoren haben gezeigt, daß künstliche Kinfettung (Züehtung auf Butteragar) auch solchen Bakterien Säurefestigkeit geben kann, die sie normaler Weise nicht besitzen.

Die spezifische Färbbarkeit der Bakterien ist also, der Ansicht der meisten Autoren nach, in erster Reihe ron ihrer chemischen Zusammensetzung abhängig, und diese wird von dem Nährboden, auf welchem die Bakterien gewachsen sind, zum großen Teil bestimmt. $\mathrm{Cramer}$ ), der diese Verhältnisse

1) Auclair, Jules et Paris, Louis. Constitution chimique du Bacille de Koch et de sa substance unissante ses rapports avec l'acidorésistence. Arch. de med. exp. et d'anat. patbol. 1907. Mars. pag. 129.

2) Cramer, E. Die Zusammensetzung der Bakterien in ihrer Abhängigkeit von dem Nährmaterial. Arch. f. Hygiene. 1893. XVI. pag. 195. 
Studien über d. Bed. d. pos. o. neg. Ausf. d. Gramfärb. etc. 361

eingehend untersucht hat, schreibt (1893): "Die Bakterien überhaupt und sogar ein und derselbe Bazillus besitzen keine typische Zusammensetzung, sondern ändern dieselbe je nach der Zusammensetzung des Nährmaterials, auf dem sie gewachsen; sie besitzen; namentlich was ihren Eiveißgehalt betrifft, ein hervorragendes Vermögen, sich dem Nährmaterial, auf dem sie gewachsen, zu adaptieren."

Auf dieses Adaptationsvermögen wollte ich meine Untersuchungen fußen.

Zu meinen Untersuchungen habe ich in erster Reihe den früher genannten $\mathrm{Cr}$ onquistschen Gram-negativen Diplococeus und den gewöhnlichen Gram-positiven polymorphen Hautcoccus benutzt. Bei dem Gang meiner Experimente habe ich es nötig gefunden zum Vergleich auch einige andere Bakterien zu studieren und habe ich hierzu Gonokokken auf Ascitesagar gezüchtet, zwei Colistämme, Staphylococcus pyogenes aureus von der Haut eines Diabetikers reingezüchtet, und einen aus dem Wasserleitungswasser reingezüchteten Gr a mpositiven, gelatina-verfliissigenden, $\operatorname{dem}$ Bacillus subtilis ähnlichen Bazillus benutzt.

Von der durch feuchtwarme Umschläge beeinflußten Epidermis eines Pneumoniekranken habe ich einen großen Tetracoccus mit ziegelroten Kulturen reingezüchtet. Da dieser Coccus Gram-negativ war und bei seinem Verhalten in manchen Punkten mit dem Cronquist schen Coccus Analogien zeigte, will ich hier auch über mit demselben angestellte Experimente berichten.

Der Nährboden, welchen ich in der Regel benutzte, war folgendermaßen zusammengesetzt:

Bouillon (Destilliertes Wasser 1000; zermablenes, möglichst fettfreies Rindfleisch 500) . . 10000

Peptonum siccum (Witte) . . . . . . 10 10

Agar-Agar (Lautenschläger) . . . . . . 150

Kochsalz ............ 50

$\mathrm{Na}(\mathrm{OH})$ zi neutraler Reaktion.

Neben diesem habe ich auch folgenden Nährboden benutat:

Destilliertes Wasser . . . . . . . 1000 0

Peptonum siccum (Witte) . . . . . . 20.0

Agar-Agar (Lautenschläger) . . . . . 150

$\mathrm{Na}(\mathrm{OH})$ zu neutraler Reaktion. 
Auf den letzteren waren dieKulturen spärlicher, die Bakterienindividuen aber verhielten sich der Gramfärbung gegenüber ganz ähnlich wie die auf dem gewöhnlichen Agar gewachsenen.

Die G r a m färbung wurde immer folgendermaßen ausgeführt :

1. Eine Minute in filtrierter:

Gesättigter alkoholischer Lösung von Gentianaviolett . $10 \cdot 0$

$5 \%$ Karbollösung . . . . . . . . . . . 9000

2. Eine und eine halbe Minute in!

Jod .................... 10

Jodkali . . . . . . . . . . . . 2 20

Destill. Wasser . . . . . . . . . . . 3000

3. Auswaschen mit absolutem Alkohol 1-2 Minuten.

4. Sehr kurze Wasserausspülung.

5. Eventuell (ein Teil des Präparates) Nachfärbung mit einer dünnen wässerigen Karbolfuchsinlösung.

Um die Färbung jedesma? zu kontrollieren wurden immer auf den Objektträger Testpräparate gemacht.

Bei der Beschreibung meiner Versuche will ich mit einem Bericht über meine Bestrebungen die Gra m - negativen Bakterien in Gram-positiv zu verwandeln beginnen.

Nachdem ich mich uberzeugt hatte, daß u. a. Butter, W eizenstärke, Hühnereiwei $\beta$ (falls nicht zu stark erwärmt), Peptonum siccum (Witte) sich der Gram schen Färbemethode gegenüber mehr oder weniger ausgeprägt positiv verhielten (Agar-Agar ist Gram-negativ), versuchte ich den von mir untersuchten Gram-negativen Bakterieu - den Cronquistschen Coccus, den roten Tetracoccus, den Colibazillus und den Gonococcus - in den drei erstgenannten Substanzen aufgeschwemmt nach Gram zu färben.

Es zeigte sich, daß die Mikroorganismen sich hierbei etwas verschieden verhielten.

\section{Butter.}

Auf dem Objektträger wurde mit einer Pipette ein Tropfen geschmolzene Butter aufgetragen, und in diesem wurden die Bakterien aufgeschwemmt. Nach Erwärmen über der Flamme wurde die überschüssige Butter weggegossen.

Der Cronquistsche Coccus und der rote Tetracoccus waren in Butter aufgeschwemmt deutlich Gram-positiv.

Das Bacterium coli commune wurde auch Gram-positiv, aber nicht in so ausgesprochenem Grade. 
Studien über d. Bed. d. pos. o. neg. Ausf. d. Gramfärb. etc. $\mathbf{3 6 3}$

Die Gouokokken verblieben Gram-negativ.

Auf Butteragar ${ }^{1}$ ) gezüchtet verhielten sich die drei erstgenannten Bakterien wie in der Butteraufschwemmung. Von den 24- und 48stündigen Kulturen auf Butteragar wurden die Bakterien auf gewöhnlichen Agar überimpft; die auf diesem entstandenen Kulturen bestanden aus Gram negativen Bakterienindividuen.

Meine Beobachtung über das Verhalten des Colibazillus auf Butteragar bestätigt somit die früher mitgeteilten Beobachtungen von $A . S c h$ id t.

\section{Weizenstärkekleister.}

In Weizenstärkekleister autgeschwemmt wurden der Cronquistsche Coccus und der rote Tetracoccus deutlich Gram-positiv; das Bacterium coli und der Gonococeus verblieben Gram-negativ.

Die zwei erstgenannten Kokkenarten wurden 3 Wochen lang in Stärkekleister gezüchtet. Die Tochterkulturen auf Agar waren Gramnegativ.

Wenn die, durch Aufschwemmung in Stärkekleister Gram-positiv gewordenen Kokken mit der Lugalschen Lösung behandelt wurden, färbten sie sich nicht wie der Stärkekleister blauviolett. Ihre Gram. positivität war also nicht durch eine mechanische Aufnahme von Stärke bedingt.

Daß man bei einigen Gram-negativen Bakterien durch Aufschwemmung in Stärkekleister $\mathrm{Gram}$-positive Eigenschaften hervorrufen kann, steht in gewissem Einklange mit der bei dem Bacillus butyricus (Clostridium butyricum, Bacillus amylobacter) gemachten Erfahrüng, daß bei der Kultivierung des Bazillus auf stärkehaltigem Nährboden das Protoplasma desselben Granulosegehalt zeigt.'2)

\section{Hühnereiweiß.}

Der Cronquist sche Coccus wurde, in Hühnereiweiß aufgeschwemmt, schwach Gram-positiv. Besonders die zentralen Teile des Kokkenplasmas behielten lange die blauviolette Farbe.

Der rote Tetracoccus wurde deutlicher Gram-positiv, jedoch nicht in demselben Grade wie auf Butteragar.

Das Bacterium coli und der Gonococeus verblieben Gramnegativ.

Möglich ist, daß die früher erwähnten Beobachtungen Mills und Wildes mit diesen meinen Beobachtungen zasammengestellt werden können. Die von den genannten Forschern beobachteten Bązillen waren,

1) Auf das geschmolzene Agar wurde so viel sterile Butter gegossen, daß diese beim Sohrägliegen des Rohres die Agaroberfläche deckte. Nach Erstarren wurde gelinde erwärmt und der Butterüberschuß weggegossen.

2) Günther, Carl. Einfïhrung in das Studium der Bakteriologie. 1906. VI. Auflage. pag. 480. 
dank dem Gehalt der Gewebe an irgendwelchem Eiweißstoffe, in denselben Gram-positiv, während sie, auf Nährboden übertragen, diese Figenschaft wieder verloren. Die serösen Überzüge der Organe und das Fibrin sind bekanntlich Gra m-positiv.

Aus meinen Versuchen geht also hervor, daß einige Gr a m negative Bakterien, wenn sie in Butter, in Weizenstärkekleister oder in Hübnereiweiß aufgeschwemmt sind, sich nach Gram färben. DaB dieses Gram-positiowerden einfach durch physikalische Ursachen bedingt sei, etwa so, daß die Medien durch Umhüllen der Mikroorganismen ihnen neue Farbenverhältnisse geben könnten, scheint mir dadurch ausgeschlossen, daß sich verschiedene Bakterien in diesen Aufschwemmungen der G ramfärbung gegenüber verschieden verhalten.

Die Tatsache, daß die von der mit feuchtwarmen Umschlägen behandelten Haut gezïchteten Bakterien speziell leicht sich in den Aufschwemmungen Gram-positive Eigenschaften erwerben, könnte vielleicht zu Gunsten der Hypothese einer Abstammung dieser Bakterien von Gram-positiven Bakterien, welchen durch die feuchtwarmen Umschläge eine G ram * positive Substanz entzogen worden ist, sprechen.

Meine Versuche von diesen Gram-negativen Kokken auf gewöhnlichem Agar Gram - positive Rassen zu züchten, schlugen alle fehl.

Bei längerer Züchtung des Cronquistschen Coccus und des roten Tetracoccus auf gewöhnlichem Agar zeigten sich jedoch in den der Kultur entnommenen Proben einige Gram positive Individuen. Da diese morphologisch mit den anderen Kokken des Präparates absolut identisch waren, scheint es mir sicher, daß es sich hierbei nicht um eine Verunreinigung handelte.

Versuche, Gram-positiven Bakterien Gram-negative Eigenschaften zu verleihen, habe ich mit dem polymorphen Hautcoccus, dem Staphylococcus pyogenes aureus und einem aus dem Wasserleitungswasser gezüchteten subtilisähnlichen Bazillus ausgeführt.

Zuerst versuchte ich die Prozedur der feuchtwarmen Umschläge in vitro nachzumachen. Auf in Petrischalen ausgegossenem und erstarrtem Agar wurden die Bakterien in Strichkulturen gezüchtet, dann wurde die halbe Agaroberfläche mit 
Studien über d. Bed. d. pos. o. neg. Ausf. d. Gramfärb. etc. 365

einem sterilen in sterilem Wasser gefeuchteten Stück Filtrierpapier bedeckt. Die feuchten Filtrierpapierstücke wurden dreimal täglich erneuert und der Thermstat auf $40^{\circ} \mathrm{C}$. gestellt. Nach 5 Tagen waren die Bakterien noch Gram-positiv und ihre Tochterkulturen auf Agar waren es auch. Durch die vielen Manipulationen waren aber sämtliche Petrischalen mit fremden Bakterien verunreinigt.

Von dem Gedanken ausgehend, daß durch die feuchten Umschläge möglicherweise irgendwelche den positiven Ausfall der Gramfärbung bedingende Substanz ausgelaugt wurde, schwemmte ich die Bakterien in sterilem Wasser auf, das zweimal täglich zentrifugiert und erneuert wurde. Nach 6tägigem Auslaugen waren die Bakterien und ihre Tochterkulturen ebenso Gram-positiv wie anfangs.

Das Mißlingen aller dieser Versuche beweist aber meines Erachtens nicht unbedingt, daß die Hypothese der durch die feuchtwarmen Umschläge bedingten Veränderungen des Grampositiven Hautcoccus bestimmt zu verwerfen ist. Die Entwicklungsbedingungen der Hautkokken unter den feuchtwarmen Umschlägen, wo sie auf einem undurchlässigen Nährboden relativ spärlich wachsen, sind doch in manchen Beziehungen ganz andere als in den von mir benutzten Versuchsanordnungen. Gegen die Versuche in den Petrischalen kann bemerkt werden, daß die eventuell zu extrahierende Substanz in den Agar eindringen und von dort den Bakterien wieder zu gute kommen könnte. Gegen die Extraktionsversuche mit sterilem Wasser und Zentrifugieren kann vor allem bemerkt werden, daß die Bakterien, wie es Bolton $\left.{ }^{1}\right) 1886$ gefunden hat, in sterilem Wasser sich gar nicht vermehren, wie sie es wabrscheinlich auf der Haut unter den feuchtwarmen Umschlägen tun. Man könnte ja annehmen, daß die fertig ausgebildeten Bakterien sich der Auslaugung gegenüber mebr widerstandsfähig zeigen sollten als die jungen in Bildung begriffenen.

Um die letzte Abweichung zu vermeiden, habe ich die Bakterien auch in $1 \%$ Peptonwasseraufschwemmung zweimal

1) Bolton, M. Über das Verhalten verschiedener Bakterienarten im Trinkwasser. Arb. aus dem hygien. Instit. zu Göttingen. Erste Abteilung. Leipzig. 1886. 
täglich wie oben zentrifugiert. Die Bakterien und ihre Tochterkulturen waren nach 6 Tagen immer Gram-positiv.

Da die Auslaugungsversuche nicht zu gewünschtem Resultat geführt hatten, bestrebte ich mich den Gram-positiven Bakterien durch Verdauung in Pepsin-, in Papayotin- und in Pankreonwasser Gram-negative Eigenschaften zu verleihen.

$\mathrm{Zu}$ diesen Experimenten wurden immer 24 Stunden alte Kulturen benutzt. Die Verdauung fand bei $37^{\circ}$ statt.

\section{Pepsin.}

Die Bakterien wurden auf Objektträgern fixiert und in die folgende Flüssigkeit getaucht:

Pepsinum siccum (Langen beck) . . . 3 0

Acid. hydrochloric dilut. . . . XXX Tropfen

Destilliertes Wasser... . . . 1000

Der polymorphe Hautcoceus und der Staphylococcus waren noch nach 5tägiger Pepsinverdauung gat geformt and Gram-positiv. Nach 10 tägiger Pepsinverdaunng waren bei den Hautkokken etwa dis Hälfte der Kokken eines Präparates gut erhalten und Gram-positiv, die übrigen waren schwach oder gar nicht von Fuchsin gefärbt, meist geschrumpft und mißgeformt. Die Staphylokokken waren alle nach 10 Tagen Gramnegativ, schlecht von der Fuchsinlösung gefärbt, geschrumpft und mißgeformt.

Der Bazillus zeigte sich nach 24 Stunden Pepsinverdauung als feine, etwa ein Drittel der ursprünglichen Bazillen im Diameter messende Gram-negative Stäbchen, in wolchen keine Sporen zu entdecken waren. Mit L o effl er schem Methylenblau gefärbt gaben die Bazillen dasselbe Bild.

Die drei genannten Bakterien wurden dann von 24stündigen Agarkulturen in der angegebenen Pepsinlösung aufgeschwemimt und in den Brutofen gebracht. Es zeigte sich nun, daß der Hautcoccus und der Staphylococeus nach 2 bis 3 Tagen noch auf gewöhnlichem $A$ gar reproduktionsfähig waren uud Gram-positive Tochterkulturen ergaben. Nach dem 5. oder 6. Tag konnten aber keine Tochterkulturen mehr erhalten werden, obwohl die Kokken in der Pepsinlösung ihre Form und ihre Färbbarkeit vollständig behalten hatten.

Ganz abweichend verhielt sich der Bazillus in der Pepsinaufschwemmung; noch nach 10tägiger Pepsinverdauung war er auf gewöhnlichem Agar reproduktionsfähig und gab Gram-positive, denjenigen in der Ausgangskultur ganz ähnliche Bazillen.

Das Ausseben der Bazillen in der Pepsinwasseraufschwemmung war auch eine andere als das der in Pepsin verdauten auf dem Objektträger fixierten Bazillen. In der Aufschwemmung waren nach 5 Tagen die meisten Bazillen ganz degeneriert und in amorphe, schlecht tingierbare, Gra m-negative Massen verwandelt. Doch waren auch spärliche, schlanke, 
Studien über d. Bed. d. pos. o. neg. Ausf. d. Gramfärb. etc. 367

schwach Gram-positive Bazillen mit bei einigen deutlich hervortretenden Sporen in den Präparaten zu finden.

Aufgeschwemmt in:

Pepsinum siccum (Langenbeck) . . . . 3.0

Acid. hydrochloric. dilnt. . . . XXX Tropfen

Bouillon . . . . . . . . . 100.0

verhielten sich die drei genannten Bakterien ganz ähnlich wie in dem Pepsinwasser.

Daß die zwei Kokkenarten nach der Pepsinverdauung, obgleich tot, ihre Färbungsfähigkeit gut behielten, steht im Einklange mit einigen früheren Beobachtungen. So fand Kita sato (1892), daß auch abgestorbene Tuberkelbazillen Im Auswurf normale Färbung annehmen; so zeigt sich die Färbbarkeit nach Radzievski (1888) beim Colibazillus nach vorsichtiger Abtötung mit Chloroform völlig intakt und das gleiche konnten Baumgarten und Bra em (1889) für Milzbrandbazillen, beim Absterben in destilliertem Wasser, in Bezug auf die Gentianaviolettfärbung nachweisen. Für den polymorphen Hautcoccus und für den Staphylococcus habe ich gefunden (1901), daß sie auf $5 \%$ Traubenzuckeragar gezüchtet nach 10-15 Tagen abgestorben sind und dennoch ihre volle Färbbarkeit noch mehrere Wochen später behalten.

Der gelatineverflüssigende, also selbst fermentbildende und peptonisierende Bazillus konnte, in Gegensatz zu den Kokken, welche keine peptonisierenden Eigenschaften besaßen, in der Pepsinlösung leben.

In abgetötetem Zustande verhielt sich der Bazillus bei der Pepsinverdauung anders, als wenn er lebend in der Pepsinlösung aufgeschwemmt wurde und diese Tatsache hat vielleicht ein Analogon in dem Verhalten der stärkehaltigen Mundbakterien, welche, obgleich sie im stärkeverdauenden Speichel leben, doch ihren Stärkegehalt bewahren können.

Papayotin (3\% Wasserlösung).

Nach 4tägiger Verdaung waren die auf dem Objektträger fixierten Hautkokken und Staphylokokken sämtlich Gram-negativ und mit Fuchsin gefärbt zeigten sie etwas verwischte Konturen.

Der Bazillus dagegen zeigte nach 4tägiger Verdauung noch einzelne normalgefärbte $\mathrm{Gram}$ - positive Individuen. Die übrigen nach $\mathrm{Gram}$ sehr schwach gefärbten Bazillen waren schlank und trugen recht deutliche Sporen. 
Da die Papayotinlösung nicht ohne Einbuße ihrer eiweißverdauenden Eigenschaften sterilisiert werden könnte, mußte ich von Aufschwemmungsversuchen mit Bakterienkulturen absehen.

Pankreon (eine Tablette von $1 / 4 g$ auf $100 \mathrm{ccm}$ Wasser +5 Tropfen $\mathrm{K}(\mathrm{OH})$-Lösung).

Die auf dem Objektträger fixierten Hautkokken und Staphylokokken waren noch nach 7tägiger Verdaung unverändert und Gram-positiv.

Der Bazillus zeigte nach 6 Tagen nur einzelne Individuen, welche die ursprüngliche Form und die Fähigkeit, sich nach Gram zu färben, behalten hatten, die übrigen waren zu feinen Gram-negativen Stäbchen, in welchen Sporen nicht zu entdecken waren, verwandelt.

In Pankreonwasseraufschwemmung blieben die Bakterien alle gut bei Leben und gaben nach 14 Tagen auf Agar Gram-positive Kulturen.

Da bei den Bakterien das positive Ausfallen der Gramfärbung mit der Säurefestigkeit sehr viele Anknüpfungspunkte zu haben scheint, habe ich noch einen in der ron mir benutzten Papayotinlösung lebenden großen und dicken Gram-positiven Bazillus, welcher bei der Ziehlschen Färbung sich als teilweise säurefest zeigte, etwas näher untersucht. Die Sporen und einige Bazillen (die juingsten?) waren ausgeprägt säurefest und diese säurefesten Individuen hatten nach der $\mathrm{Ziehlfärbung}$ eine ovalere Form als die übrigen. Nach Gram gefärbt waren alle Bakterien gleich.

Auf dem Objektträger fixiert und in Verdauungsfliissigkeiten eingetaucht verhielten sich die Bazillen folgendermaßen :

In 3\% Papayotinlösung behielten die Bazillen noch nach 10 Tagen ihre ursprüngliche Form und die Fähigkeit sich nach Gram zu färben.

In $3 \%$ Pepsinlösung waren nach 4 Tagen von den Bazillen nur Gram-negative geschrumpfte Hüllen ohne Inhalt übrig.

In Pankreonlösung waren nach 4 Tagen die säurefesten Formen gut erhalten und Gram-positiv, die übrigen waren etwas geschrumpft und entfärbten sich nach Gram. Nach 10 Tagen waren nur Gram-negative geschrumpfte Hüllen übrig.

Diese Bazillen färbten sich durch Lugolsche Flüssigkeit nicht dunkelblau. Die Substanz, welche das positive Ausfallen der Gramfärbung bedingte, war also keine Stärke, obgleich 
Studien über d. Bed. d. pos. o. neg. Ausf. d. Gramfärb. etc. 369

sie bei den älteren (?) Bazillformen recht schnell, bei den jüngeren (?), säurefesten Formen langsamer in der Pankreonlösung verdaut wurde, sondern es handelte sich wahrscheinlich um eine sog. Hemicellul ose. Diese von E. Schulze $\mathrm{S}^{\mathbf{1}}$ (1893) beschriebenen Hemicellulosen sind leicht invertierbare Kohlen hydrate und kommen, wie es $\mathrm{N}$ is himura 1894 gezeigt hat, in mehreren Bakterien in reichlichen Mengen vor.

Will man aus den beschriebenen Experimenten sich ein Urteil über die Bedingungen der Gramschen Färbemethode bei den Bakterien bilden, so scheint es mir in der Richtung gehen zu müssen, daß zwischen den Bedingungen der Säurefestigkeit, wie sie Auclair und Paris festgestellt haben und den Bedingungen des positiven Ausfallens der Gramfärbung, die größten Analogien vorhanden sind.

Das positive Ausfallen der Gram-färbung ist in erster Linie durch die chemische Zusammensetzung der Bakterien bedingt. Es ist aber nicht an den Gehalt der Bakterien, an eine gewisse Substanz gebunden, sondern scheint vielmehr von ihrem Gehalt an rerschiedenen Stoften - Fett, Stärke, Hemicellulose, gewisse Eiweißkörper - abhängig zu sein.

Sehr wahrscheinlich ist auch, daß für das positive Ausfallen der Gramfärbung noch eine spezielle zusammengedrungene physikalische Natur der Bakterienzelle notwendig ist, eine Natur, die das Eindringen der Färbeflüssigkeit schwieriger macht, aber die auch dem Auswaschen durch absoluten Alkohol der von $\mathbf{J}+$ Pararosanilin + irgendwelcher Substanz aus der Bakterienzelle gebildeten schwerlöslichen Verbindung noch gröBeren Widerstand entgegensetzt.

Aus meinen Untersuchungen geht noch hervor, daß das Verhalten einiger Bakterien der Gramschen Färbemethode gegenüber küustlich beeinflußt werden kann. Einige sonst Gra mnegative Bakterien verhalten sich, wenn sie in Fett, Eiweiß oder Stärkekleister aufgeschwemmt sind, Gram-positiv und einige andere, sonst Gram - positive Bakterien, lassen sich nach

1) Schulze, E. und Castoro, N. Beiträge zur Kenntnis der Hemicellulosen. H o p pe-S e y l ers Zeitschr. für physiol. Chemie. 1893. XXIX. 318. 
der Einwirkung vonVerdauungsflüssigkeiten nicht mehr nach $\mathrm{G} \mathrm{ram}$ färben. Bei diesen letzteren Versuchen habe ich gefunden, da B Pepsin-, Papayotin- und Pankreonverdauung auf verschiedenen Bakterien ganz verschiedene Wirkungen ausüben.

Bei den Tochterkulturen habe ich eine Vererbung der veränderten Eigenschaften nicht nachweisen können.

Meinem Freunde Professor Dr. Ernst Ehrnrooth, der mir gestattet hat, meine Untersuchungen in dem Laboratorium des gerichtlich-medizinischen Instituts auszuführen, sage ich hierfür auch an dieser Stelle meinen besten Dank. 